\title{
Enhancement the stability of power system using optimal location of FACTS devices
}

\author{
Ali Najim Abdullah, Ahmed Majeed Ghadhban, Hayder Salim Hameed, H. I. Hussein \\ Department of Electrical Power and Machines, Collage of Engineering, University of Diyala, Iraq
}

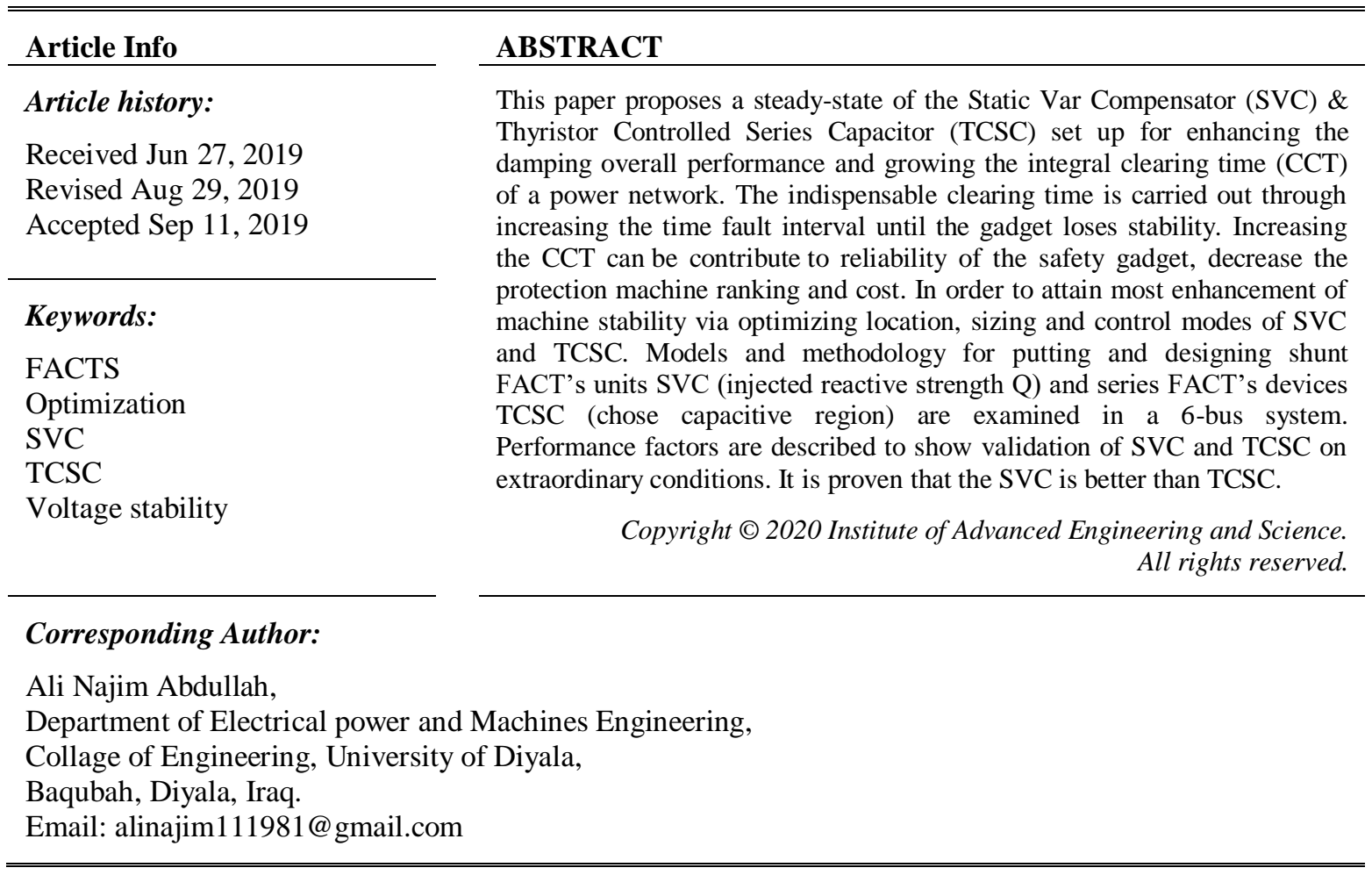

\section{INTRODUCTION}

In late decades, with the deregulation of the power market, because of the opposition between utilities the quantity of unplanned conveyed power increments. On the off chance that these trades are not controlled, a few lines may get to be over-burden. This has come about into the trouble in damping low recurrence motions which restricts the ability to transmit power and prompts framework division. Then again, the quick development of power demand prompts the responsive power arranging issue particularly under possibilities. subsequently, there is an issue in compensating touchy force prerequisite and keeping up the bus voltage inside tasteful cutoff points.

Voltage stability of energy structures is one of the noteworthy perspectives in electric powered energy framework operation. Influential damping is sure the modes of electromechanical damping or motions amongst of Synchronous turbines interconnected in a PS framework [1]. While the excitation of generator framework for PSS to keep up excitation succeed and steadiness, however it is now not very good to manage the dependability of force framework because of deficiencies or over-burdening close to the generator terminals [2-3]. Accordingly, analysts have been dealing with this issue for quite a whilst trying to find an answer. One of the influential techniques for improving transient strength is to make use of the bendy AC transmission gadget (FACTS) controller devices [4-6]. Anyway, influential damping will improve with the use of the damping stabilizer [7-8]. Flexible AC Transmission System (FACTS) gives more interest at final years. It uses high current energy digital gadgets to manipulate of a transmission system such as voltage, power flow and stability, etc. FACTS gadgets can be linked with transmission line in different ways series, shunt, or a combination between them. The definition and time period of a type of FACTS are described in references [9-10]. Two types of FACTS gadgets are very efficient and successful to increase the energy 
switch functionality of a line, in so a long way as the thermal limitations allow while preserving the equal level stability [11-12]. It is essential to locate the position, measurement and type of these controller devices due to the fact of its substantial costs. The Studies, investigation and realizations already have achieved their abilities in a constant kingdom or dynamic preconditions [13-14]. The voltage stability trouble is coupled with reactive electricity must be tackled by giving enough reactive energy lower back to the discriminating nodes. The reactive power management can be achieved by an exchanged capacitor financial institution in nature generally is discreted. The late pattern is to supplant the banks of capacitor for SVC to have a delicate manipulate in reactive strength (Q). SVC has the capability of presenting alterably movable reactive energy inside the minimum and maximum limits [15-16].

To improve stability of power system and to tackle the reactive power planning issue, flexible AC transmission system (FACTS) devices (FACTS) are broadly utilized by power framework utilities. FACT'S are controllers utilized as a part of electric power frameworks radiating from late improvement of power electronics hardware that are extremely useful in improving the proficiency of power framework operation. Finally, in this paper, test the approval of Fact's devices SVC \& TCSC to managing the power stream of a TL, damping the power oscillations, and improving power system stability. Simulation results have been completed in the (6-bus) framework. To validate the presented models.

\section{MATHEMATICAL MODELS}

\subsection{Mathematical Model of Power System}

The two next equations describe the power flow (PF) with FACTS devices:

$$
\begin{aligned}
& \mathrm{P}_{\mathrm{Gi}}-\mathrm{P}_{\mathrm{Di}}-\sum_{\mathrm{j}=1}^{\mathrm{n}}\left|\mathrm{V}_{\mathrm{i}}\right|\left|\mathrm{V}_{\mathrm{j}}\right|\left(\mathrm{G}_{\mathrm{ij}}-\operatorname{FACTS} \sin \left(\delta_{\mathrm{ij}}\right)+\mathrm{B}_{\mathrm{ij}}-\operatorname{FACTS} \sin \left(\delta_{\mathrm{ij}}\right)\right)=0 \\
& \mathrm{Q}_{\mathrm{Gi}}-\mathrm{Q}_{\mathrm{Di}}-\sum_{\mathrm{j}=1}^{\mathrm{n}}\left|\mathrm{V}_{\mathrm{i}}\right|\left|\mathrm{V}_{\mathrm{j}}\right|\left(\mathrm{G}_{\mathrm{ij}}-\operatorname{FACTS} \sin \left(\delta_{\mathrm{ij}}\right)-\mathrm{B}_{\mathrm{ij}}-\operatorname{FACTS} \sin \left(\delta_{\mathrm{ij}}\right)\right)=0 \\
& \left|\mathrm{~V}_{\mathrm{j}}\right|_{\min } \leq\left|\mathrm{V}_{\mathrm{j}}\right| \leq\left|\mathrm{V}_{\mathrm{j}}\right|_{\max } \\
& \delta_{\mathrm{ij}} \leq \delta_{\mathrm{ij}} \max
\end{aligned}
$$

Where,

$\mathrm{P}_{\mathrm{Gi}}, \mathrm{Q}_{\mathrm{Gi}}$ : Generated real and reactive power at bus $\mathrm{i}$;

$\mathrm{P}_{\mathrm{Di}}, \mathrm{Q}_{\mathrm{Di}}$ : Real power and reactive power of load at bus $\mathrm{i}$;

n: Bus number;

$\mathrm{G}_{\mathrm{ij}}, \mathrm{B}_{\mathrm{ij}}$ FACT's: Real \& Imaginary parts of $(\mathrm{i}, \mathrm{j})$ th element of matrix admittance network with FACTS controller;

$\delta_{\mathrm{ij}}$ : phase angle Difference between (i and $\mathrm{j}$ );

$\left|\mathrm{V}_{\mathrm{j}}\right|_{\text {min }},\left|\mathrm{V}_{\mathrm{j}}\right|_{\text {max }}:$ Max. and min. voltage magnitude at bus $\mathrm{i}$.

\subsection{Steady State Models of Fact's Devices SVC}

The most important motive of SVC is regulated voltage at vulnerable factors in the power system network. Figure 1 suggests the single line format of a transmission line that is compensated included SVC at bus $\mathrm{j}$, the model for strength injection SVC can be illustrated as in Figure 2. In this case study, the SVC is dealt with a variable capacitance, the place $I_{S V C}$ is the complicated injected cutting-edge of SVC at node $\mathrm{j}$ [17-18]. It can be achieved as follows:

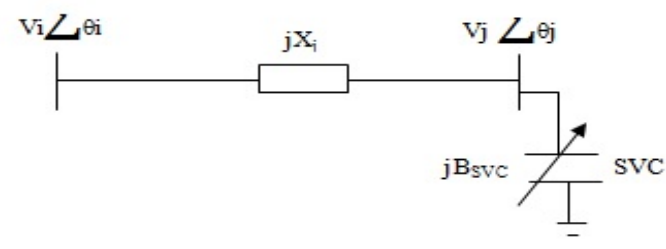

Figure 1. Single line diagram of compensated TL

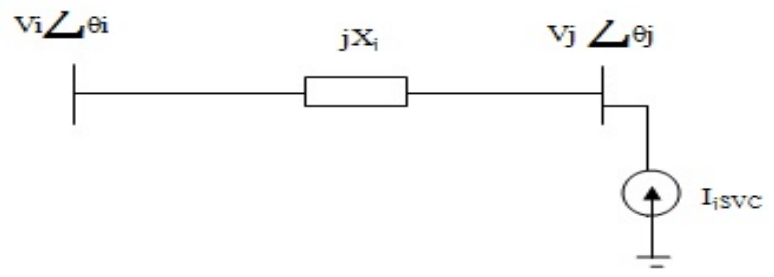

Figure 2. Power injected model of SVC 
The SVC can be actes as a capacitive behavior or as inductive mode for absorbing or to generate the reactive power (VAr). The SVC is appeare as a variable shunt susceptance connected to the end bus of TL or at the midpoint of it [19]. The SVC device is a voltage managed system and its susceptance ought to be specified for the rules of bus voltage at the preferred value. The normal values of the SVC are identical to the power system values. In this work, we can be discribted as below:

$$
\begin{aligned}
& -100 \leq Q_{S V C} \leq+100 \\
& \mathrm{I}_{\mathrm{SVC}}=-j B_{S V C} V_{K}
\end{aligned}
$$

The fundemantal frequency TCR equivalent reactance $X_{T C R}$.

$$
X_{T C R}=\frac{\pi X_{L}}{\sigma-\sin \sigma}
$$

Where $\sigma=(\pi-\alpha), X_{L}=\omega L$

At $\alpha=90^{\circ}$, TCR will be fully conducts and the $X_{T C R}$ becomes $X_{L}$, while at $\alpha=180^{\circ}$, TCR is blocked and its $X_{T C R}$ becomes infinite. The combination of $X_{C}$ and $X_{T C R}$ in parallel will be cause to determine SVC effective reactance $X_{S V C}$.

$$
X_{S V C}=\frac{\pi X_{C} X_{L}}{X_{C}[2(\pi-\alpha)+\sin 2 \alpha]-\pi X_{L}}
$$

Where $X_{C}=1 / \omega c$

$$
Q_{K}=-V_{K}^{2}\left(\frac{X_{C}[2(\pi-\alpha)+\sin 2 \alpha]-\pi X_{L}}{\pi X_{C} X_{L}}\right)
$$

\subsection{Model of FACTS Devices TCSC (Steady State)}

Figure 3 shows the Single line diagram of transmission line together with TCSC, its performed by lumped $\pi$ equivalent parameters.

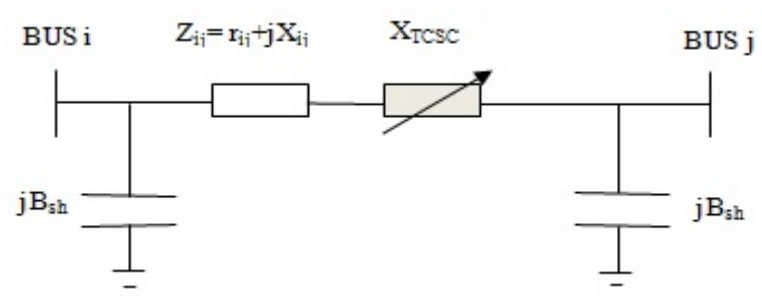

Figure 3. Single line diagram of compensated transmission line together with TCSC

The TCSC acts as capacitor or inductor behavior in steady state condition, in order to change the branch impedance. The value of TCSC with variable series reactance as a function of line reactance of $X_{L}$, where the device is located [20]. The minimum and maximum value of reactance of TCSC can be determined from (8).

$$
-0.8 X_{L} \leq X_{T C S C} \leq 0.2 X_{L} p . u
$$

The power injection of TCSC incorporated within the TL as shown in Figure 4 [20]. The difference of line admittance of TCSC is given in (9).

$$
\begin{aligned}
& X_{T C S C}=-X_{C}+K_{1}\left(2 \sigma+\sin 2 \sigma-K_{2} \cos 2 \sigma\left(\omega^{-} \tan \omega^{-} \sigma\right)-\tan \sigma\right) \\
& \text { Where; } \sigma=(\pi-\alpha), \omega^{-}=\sqrt{\frac{X_{C}}{X_{L}}}
\end{aligned}
$$




$$
X_{L C}=\frac{X_{C} X_{L}}{X_{C}-X_{L}}, K_{1}=\frac{X_{C}+X_{L C}}{\pi}, K_{2}=\frac{\left(X_{L C}\right)^{2}}{\pi X_{L}}
$$

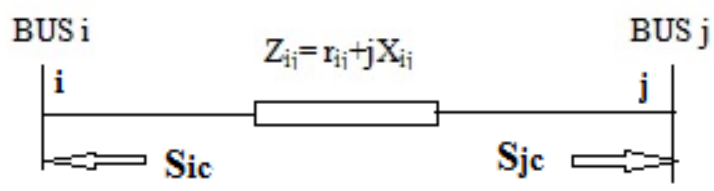

Figure 4. Power Injection model of TCSC

$$
\Delta y_{i j}=y_{j}-y_{i j}=\left(g_{i j}^{\prime}+j b_{i j}^{\prime}\right)-\left(g_{i j}+j b_{i j}\right)
$$

Where,

$$
\begin{aligned}
& g_{i j}=\frac{r_{i j}}{\sqrt{r_{i j}^{2}+x_{i j}^{2}}} ; b_{i j}=\frac{-x_{i j}}{\sqrt{r_{i j}^{2}+x_{i j}^{2}}} \\
& g_{i j}^{\prime}=\frac{r_{i j}}{\sqrt{r_{i j}^{2}+\left(x_{i j}+x_{T C S C}\right)^{2}}} ; b_{i j}=\frac{-\left(x_{i j}+x_{T C S C}\right)}{\sqrt{r_{i j}^{2}+\left(x_{i j}+x_{T C S C}\right)^{2}}}
\end{aligned}
$$

When TSCS is installed between (i \& j) buses the admittance matrix can be obtained from (14).

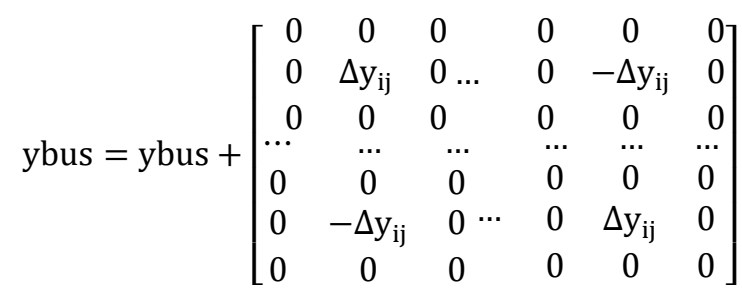

\section{SIMULATION RESULTS AND ANALYSIS (10 PT)}

The 6-bus test system is used to evaluate the effectiveness of SVC and TCSC models developed in this paper. Figure 5 shows the Six bus 3 Generator systems, with $400 \mathrm{kv}$ and 100MVA base has been considered. The data of system [14] shown in APPENDIX A. two cases are considered, SVC is connected at bus 5 and, then at bus6, TCSC connected between line2 (1-4). After that we made fault on many line in 6 bus system to see the validation of FACTS devices (SVC\& TCSC). And which one is better to minims losses and reduction the damping.

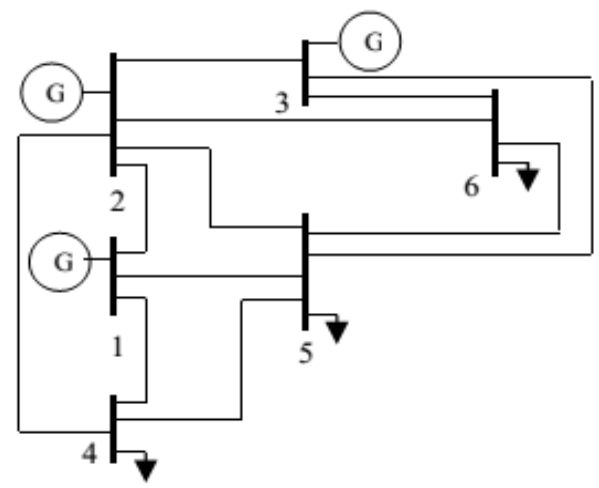

Figure 5. Six bus 3 Generator systems 


\subsection{SVC Set Up}

The SVC connected for many objectives by utilities in transmission applications. The main role is as a rule for fast voltage control at powerless focuses in a system. The SVC may be established at the midpoint or at the end of transmission line. In this paper SVC is associated at transport 5 and the all out losess was (10.069MW) as shown in Figure 6.

The total loses after installed SVC at bus 5 was (-68 MVAR, 10.069 MW). As shown in Figure 7. And the Optimal Location and Size of SVC with details shown in Table 1.

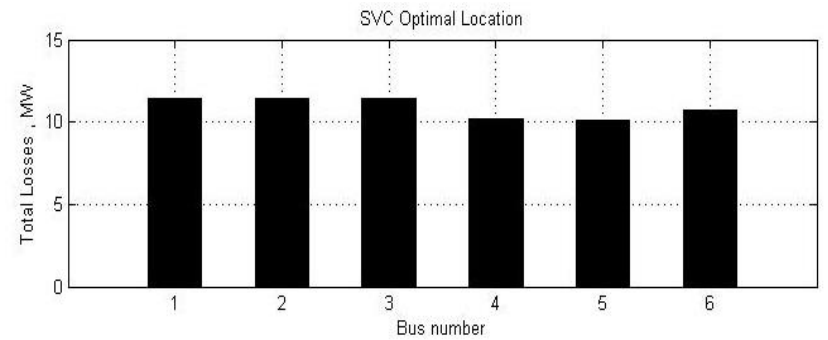

Figure 6. SVC Optimal Location

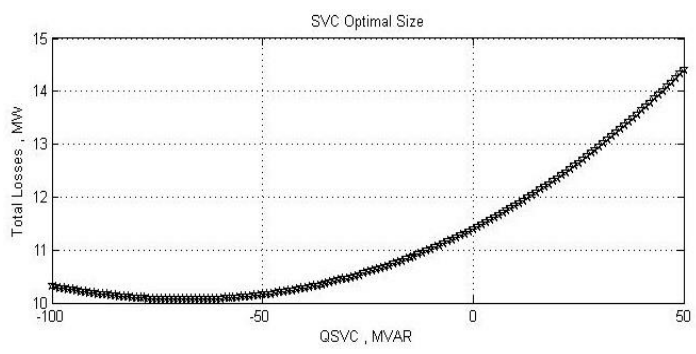

Figure 7. SVC Optimal size

Table 1. Optimal Location and Size of SVC

\begin{tabular}{ccccccc}
\hline \multicolumn{7}{c}{ Optimal Location and Size of SVC } \\
\hline Bus no. & 1 & 2 & 3 & 4 & 5 & 6 \\
$Q_{S V C}$ in MVAR & $\ldots$ & $\ldots$ & $\ldots$ & -66 & -68 & -66 \\
Total Losses in MW & 11.397 & 11.397 & 11.397 & 10.226 & 10.069 & 10.681 \\
\hline
\end{tabular}

\subsection{The Installation of TCSC}

TCSC is one of the most significant FACTS family, Which has been used for many years for improving power transfer and system stability. TCSC is connected on line2 (1-4), and the total losess was (11.02MW).as shown in Figure 8.

The total loses after installed TCSC on line2 (1-4) was (-0.086 P.u, 11.02MW). As shown in Figure 9. And the Optimal Location and Size of TCSC with details shown in Table 2.

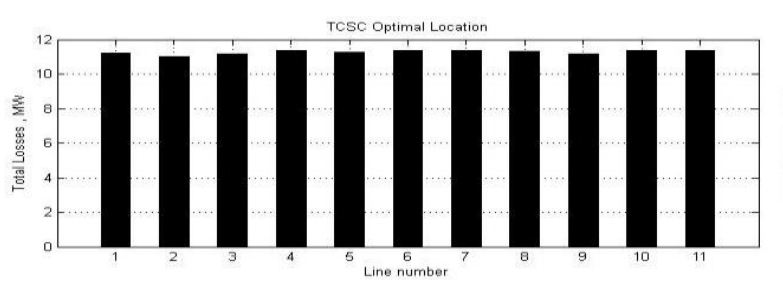

Figure 8. TCSC Optimal Location

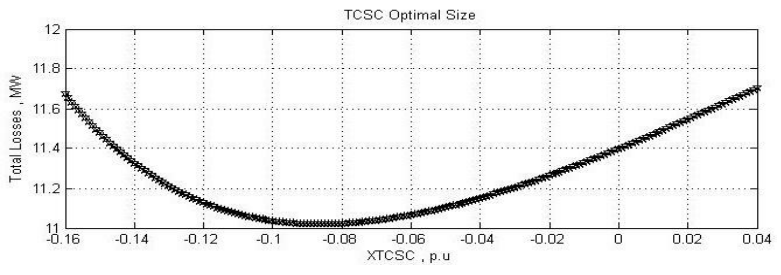

Figure 9. TCSC Optimal size

Table 2. Optimal Location and Size of TCSC

\begin{tabular}{ccc}
\hline \multicolumn{3}{c}{ Optimal Location and Size of TCSC } \\
\hline Line Number & $\mathrm{X}_{\text {TCSC }}$ in p.u & Total Losses in MW \\
1 & 0.04 & 11.193 \\
2 & -0.086 & 11.02 \\
3 & -0.094 & 11.149 \\
4 & -0.102 & 11.372 \\
5 & 0.02 & 11.282 \\
6 & -0.029 & 11.39 \\
7 & 0.04 & 11.352 \\
8 & 0.052 & 11.336 \\
9 & -0.06 & 11.173 \\
10 & 0.08 & 11.378 \\
11 & -0.25 & 11.369 \\
\hline
\end{tabular}




\subsection{Evaluation of Critical Clearing Time CCT}

To achieve the Critical clearing time exhibitions of the PS, the heap is expanded bit by bit and burden stream consider is executed for the strength examine. The CCT can be gotten by expanding the time interim of the shortcoming step by step until the conscious framework loses its security. To contemplate the incredible of the FACT's devices (SVC and TCSC). Deficiency shows up on bus2 line1(1-2) and this line expelled as appeared in Figures 10 and 11, Fault shows up on bus3 line4(2-3) and this line expelled as appeared in Figures 12 and 13. The flaw interim time increments bit by bit up till the framework loses its security and afterward the CCT can be resolved. Table 3. demonstrates the examined power framework basic clearing time with and without introducing FACT's gadgets (SVC and TCSC). The impact of introducing SVC and TCSC in expanding the CCT was clear. This will support to pick the reasonable security framework.

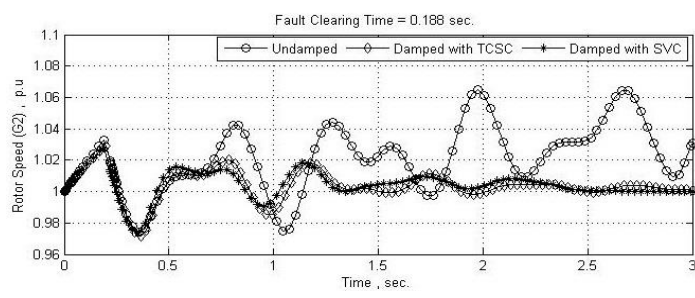

Figure 10. Fault Clearing Time $0.188 \mathrm{sec}$ at Bus2. Rotor speed for $\mathrm{G} 2$

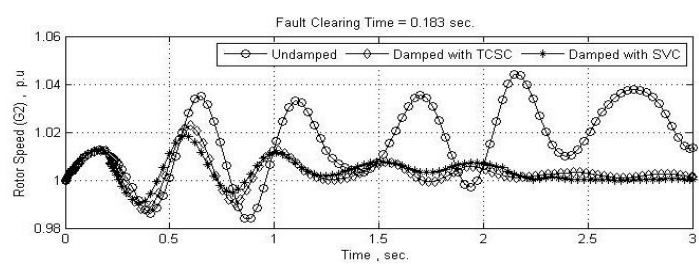

Figure 12. Fault Clearing Time $0.183 \mathrm{sec}$ at Bus3. Rotor speed for $\mathrm{G} 2$

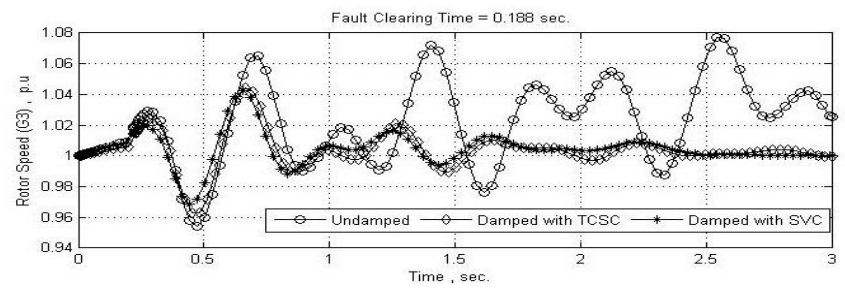

Figure 11. Fault Clearing Time 0.188sec at Bus2, Rotor speed for $\mathrm{G} 3$

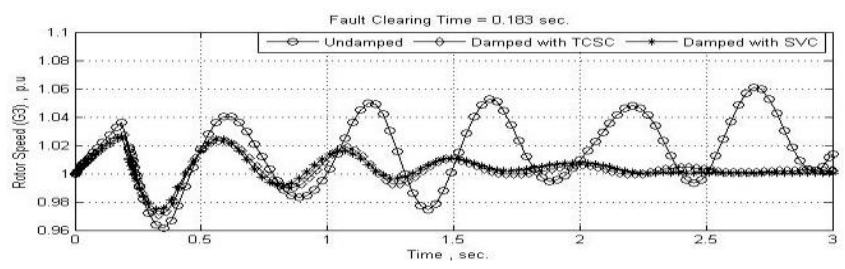

Figure 13. Fault Clearing Time $0.183 \mathrm{sec}$ at Bus. Rotor speed for $\mathrm{G} 2$

Table 3. Critical Clearing Time (CCT ) in M.Sec

\begin{tabular}{cccc}
\hline & \multicolumn{3}{c}{ Critical Clearing Time (CCT ) in m.sec. } \\
\hline Fault Locations & Undamped & Damped with TCSC & Damped with SVC \\
At Bus 2 Line 1 & 188 & 221 & 234 \\
At Bus 3 Line 4 & 183 & 207 & 219 \\
At Bus 2 Line 5 & 242 & 291 & 297 \\
At Bus 1 Line 3 & 192 & 232 & 276 \\
At Bus 2 Line 6 & 251 & 284 & 294 \\
At Bus 3 Line 9 & 186 & 226 & 287 \\
\hline
\end{tabular}

\section{CONCLUSION}

In this paper steady-state of FACT's devices for power system network solution was developed for desired power transferred capabilities discussed in details. In order to find the optimal location and size of FACT's devices and to evaluate the effects of these devices on a power system network. A proposed idea has been tested on 6- bus system. To make obvious the performance of the proposed models, it shows as the minimizing the losses of power system (real power) with best size \& optimal location of FACTS devices. Real and reactive power improved after placing FACTS devices. It is shown that the SVC is better than TCSC.

\section{REFERENCES}

[1] G. Lof P.A., Hill D.J., "Voltage stability indices for stressed power systems," IEEE Journal Power Systems, vol. 8, pp. 326-335, 1993. 
[2] N. C. Mithulananthan, C.A. Reeve, J., "Tuning, performance and interactions of PSS and FACTS controllers," IEEE Power Engineering Society Summer Meeting, vol. 2, pp. 981-987, 2002.

[3] H. M. B. A. Tahri, A. Allali, T. Fatima,, "A Multi-Variable LQG Controller-based Robust Control Strategy Applied to an Advanced Static VAR Compensator," Acta Polytechnica Hungarica, vol. 10, pp. 229-247, 2013.

[4] Prabha Kundur, "Power System Stability and Control," 1994.

[5] G. Rogers, "Power System Oscillations," ed. Springer, 2000.

[6] M. Hussein, "A New Scaled Fuzzy Method Using PSO Segmentation (SePSO) Applied for Two Area Power System," International Journal of Electrical and Computer Engineering (IJECE), Vol 9, No 2, 2019.

[7] M. H. Haque, "Improvement of First Swing Stability Limit by Utilizing Full Benefit of Shunt Facts Devices," IEEE Trans. Power Syst, vol. 19 No.4, pp. 1894-1902, 2004.

[8] M. K. P. Kundur, G. J. Rogers, M. S. Zywno, , "Application of Power System Stabilizers for Enhancement of Overall System Stability," IEEE Transactions on Power Apparatus and Systems, vol. 4, pp. 614-626, 1989.

[9] K. P.R. Sharma, N. Kumar, "Optimal Location for Shunt Connected FACTS Devices in a Series Compensated Long Transmission Line," Turk J. Elec. Engin., vol. 15, No. 3., 2007.

[10] G. T. H. D.J. Gotham, "Power Flow Control and Power Flow Studies for System with FACTS Devices," IEEE Transaction on Power Syst., vol. Vol.13,No.1., 1998.

[11] G.H. Hingorani, "Flexible AC Transmission System " IEEE Spectrum, 1993.

[12] Ghassan Abdullah Salman, Mohammed Hasan Ali, and A. N. Abdullah, "Implementation Optimal Location and Sizing of UPFC on Iraqi Power System Grid (132 kV) Using Genetic Algorithm," International Journal of Power Electronics and Drive System (IJPEDS), vol. 9, No. 4,, pp. 1607-1615, 2018.

[13] T. J. a. D. Overbye, C.L.,, "Improved Technique For Power System Voltage Stability Assessment Using Energy Methods" IEEE Trans. On Power Systems vol. 6, No. 4 pp. 1446-1452, 1991.

[14] Ghassan. A. S., Husham I. H., and Mohamed S. H., "Enhancement The Dynamic Stability of The Iraq's Power Station Using PID Controller Optimized by FA and PSO Based on Different Objective Functions," ELEKTROTEHNIŠKI VESTNIK, pp. 42-48, 2018.

[15] Y. H. S. Y. Xiz, Y.Z. Sum, , "Power Flow Control Approach to Power Systems with Embedded FACTS Devices " IEEE Trans. Power syst., vol. Vol. 17, No. 4, 2002.

[16] Husham I. H. and A. M. G., "A hybrid model for state estimation prediction composed of neural network and PSO algorithm for Iraqi national super grid system," International Scientific Conference of Engineering Sciences, pp. 50-55, 2018.

[17] Y.U.T. Sopl, "Coordination of TCSC and SVC for Inter Area Stabilatiy Enhencment," IEEE Transaction on power Delivery, 2000.

[18] H. I. HUSSEIN, G. A. Salman, and M. S. Hasan, "Phase Measurement Units Based FACT's Devices for the Improvement of Power Systems Networks Controllability," International Journal of Electrical and Computer Engineering (IJECE), vol. 8, No. 2, 2018.

[19] H. I. H., "Neural Network Controller Based Dstatcom for Voltage Sag Mitigation and Power Quality Issue," International Journal of Engineering and Technology (IJET), vol. 8, No.1, pp. 405-420, 2016.

[20] F. W. Allen J.Wood, "Power Generation Operation and Control " Wiley publication, 2003.

\section{BIOGRAPHIES OF AUTHORS}

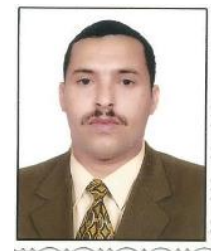

Ali Najim Abdullah was born in Diyala, Iraq, in 1981, received his B.Sc. from University of Diyala, Iraq in 2003, M. Sc. from University of Belgorod, Russia, 2013. He is currently assistant lecturer at the Department of Electrical Power and Machines Engineering, College of Engineering, University of Diyala, Iraq. Professional Strength and Skills: His current research interests are power system modeling, power quality, power stability, power reliability, renewable energy, electrical machine. He has 13 years experience in practice of Electrical engineering. He is teaching several basic subjects of the Electrical Engineering, University of Diyala, Iraq. He has 2 published papers.

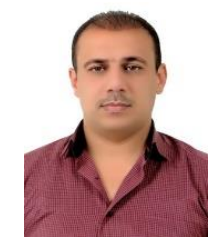

Ahmed Majeed Ghadhban was born in Diyala, Iraq, in 1978, received his B.Sc. from University Technology, Iraq in 2002, M. Sc. from University Technology of Malaysia (UTM), Malaysia, in 2012. He is currently lecturer at the Department of Electrical Power and Machines Engineering, College of Engineering, University of Diyala, Iraq. Professional Strength and Skills: His current research interests are power system modeling, power quality, power stability, power reliability, renewable energy, electrical machine. He has 14 years experience in practice of Electrical engineering. He is teaching several basic subjects of the Electrical Engineering, University of Diyala, Iraq. He has 5 published papers. 

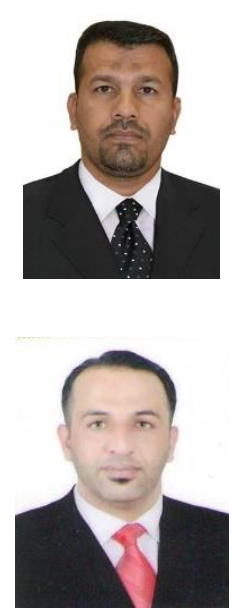

Hayder Salim Hameed was born in Diyala, Iraq, in 1977, received his B.Sc. from University of Diyala, Iraq in 2002, M. Sc. from University of Baghdad, Iraq, 2014. He is currently assistant lecturer at the Department of Electrical Power and Machines Engineering, College of Engineering, University of Diyala, Iraq. Professional Strength and Skills: His current research interests are power system modeling, power quality, power stability, power reliability, renewable energy, electrical machine drives and power electronics control. He has 13 years experience in practice of Electrical engineering. He is teaching several basic subjects of the Electrical Engineering, University of Diyala, Iraq. He has 2 published papers.

Husham I. Hussein was born in Baghdad, Iraq, in 1978, received his B.Sc. from University Technology / Iraq in 2002, M.Sc. from University Technology of Malaysia (UTM) in 2012. He is currently assistance professor in Department of Electrical Power and Machines Engineering, College of Engineering, University of Diyala, Iraq. Professional Strength and Skills: current his research interests are optimization power system, power quality, power system state estimation, and Renewable Energy. He has good experience in practice of Electrical engineering in different fields such as installation of industrial plants and other electrical design and executing works. He is teaching several basic subjects of the Electrical Engineering, University of Diyala - Iraq. He is a member of IAENG. 